Kanowski, J. (2010) What have we learnt about rainforest restoration in the past two decades? Ecological Management and Restoration 11:2-3

[Guest editorial]

\title{
What have we learnt about rainforest restoration in the past two decades?
}

\author{
By John Kanowski
}

Quite a lot, actually.

There are three main types of rainforest restoration practised in tropical and subtropical Australia: remnant restoration, regrowth management and the reforestation of cleared land. Most of this activity has been conducted in the past two decades. Enough time has elapsed to evaluate the outcomes of these projects, and consider how things might be done in the future.

The restoration of rainforest remnants is now a mature craft, with well-tested, clearly defined protocols for a range of sites and situations (Joseph 1999; Big Scrub Rainforest Landcare Group 2005). Most major rainforest remnants in (subtropical) northern New South Wales (NSW) have now been subject to restoration work, significantly reducing threats from invasive vines. In my view, the maturity of remnant restoration owes much to the long-term funding of projects, allowing the continued employment of practitioners and enabling them to invest effort in sites, reflect on outcomes and revise their approaches over time.

Regrowth management has also mainly been practised in northern NSW, where secondary forests dominated by the exotic tree Camphor Laurel (Cinnamomum camphora) are extensive. Regrowth management is under less 'central control' than remnant restoration and, as a result, several different approaches have been developed for converting Camphor Laurel stands to regenerating rainforest (Kanowski et al. 2008b). Some large areas have been treated, with encouraging results (Woodford 2000; Lymburner et al. 2006). Again, I believe that long-term funding of projects has been a key factor in the development of effective restoration techniques, for the reasons outlined above.

Of the three types of rainforest restoration, reforestation is the most extensive, with several thousand hectares of cleared land being replanted in tropical and subtropical Australia. In (tropical) north Queensland, most reforestation projects were funded by governments; in the subtropics, many were funded by landholders themselves. Nevertheless, similar planting models have been employed in both regions, reflecting the influence of key practitioners (Goosem and Tucker 1995; Kooyman 1996) who drew on concepts developed by pioneering rainforest ecologists Lenn Webb, Geoff Tracey and Alex Floyd. The dominant planting model has involved the establishment of a diverse mix of rainforest trees, from a range of successional guilds, planted at high densities. A less widely implemented model has used mainly early successional species ('framework' or 'early successional' model), which aimed to build diversity over time as seeds were dispersed from nearby remnants. Subsequent evaluation has demonstrated that the diverse planting model can rapidly achieve canopy closure and develop a rainforest-like structure (e.g., Tucker and Simmons 2009), 
suppressing sun-demanding grasses and weeds. In contrast, the more light-canopied 'early successional' model has generally performed poorly, at least in cleared parts of the landscape, with plantings vulnerable to weed invasion as pioneers senesce (Freebody 2007).

A comprehensive evaluation of the outcomes of rainforest plantings for biodiversity has been conducted by a research program funded by the Rainforest CRC and its successor, the Marine and Tropical Sciences Research Facility (see Catterall et al. 2004 for an overview, and numerous publications for specific outcomes for plants, beetles, ants, birds and reptiles). The results of this research have shown that diverse restoration plantings can support moderate numbers of rainforest specialist fauna within 5-10 years of establishment. In contrast, timber plantations tend to support few rainforest specialist fauna unless they are established near remnant rainforest.

It is important to note, however, that the research described above has focussed on the best available sites, rather than a random sample of established plantings, and hence has overstated the overall success of replanting projects. A recent, unbiased assessment of rainforest plantings established under the Natural Heritage Trust program (NHT) in north Queensland found, firstly, that only half the area of plantings supposedly established could be located on the ground, and secondly, of the plantings remaining, half were in 'poor' or 'very poor' condition - i.e., they had an open canopy, a weedy understorey, and were considered unlikely to progress towards rainforest without significant intervention (Taylor 2009) (Figure 1).

What were the conditions that promoted success in restoration plantings? Successful plantings had a history of long-term 'checking' and maintenance - such as 'showcase' sites, and plantings where landholders took a personal interest in the project's success. Conversely, sites that received little attention from practitioners or landholders after funding programs ceased were likely to be failures. Unfortunately, most government funding for revegetation projects has been short-term: 2-3 years, under the NHT program. In rainforest landscapes, this is hardly sufficient to achieve canopy closure, let alone maintain sites in the face of recurrent disturbances such as cyclones, which can open up established sites (Kanowski et al. 2008a).

Some rainforest restoration projects are now old enough that we can predict their likely future composition, given patterns of plants recruitment to those sites. Casual observation clearly shows that, in heavily modified landscapes, recruitment in restoration plantings is often dominated by exotic fleshy-fruited shrubs, some of which are shade-tolerant (Figure 2). Weed invasion is particularly problematical in small or narrow plantings, in plantings dominated by early successional species and in sites disturbed by cyclones, floods, drought or frost, where light levels are high. It seems plausible that, over time and without further intervention, such sites will 'regress' towards weed-dominated stands. Managed regrowth or Camphor Laurel stands that have been subject to restoration treatments are also likely to regress towards a high level of weed dominance in the future, for the same reasons, unless there is ongoing commitment to their maintenance.

With the benefit of hindsight, I would argue that past approaches to rainforest restoration have drawn too heavily on successional models derived from intact rainforest systems. Instead, we require a more sophisticated understanding of the dynamics of restored sites in heavily modified landscapes, where for example the seed rain is always likely to have a significant exotic component (Kanowski et al. 2008c). Armed with this understanding, I think it is evident that replanted, managed 
regrowth and remnant sites will all require long-term maintenance if we wish to restore native forest systems, rather than create 'new forests' (mixtures of native and exotic species).

In summary, rainforest restoration is a long-term endeavour. The short-term funding paradigm that has prevailed in many replanting projects, particularly government schemes, has served restoration objectives poorly and resulted in a great waste of money. Renewed funding for restoration projects may soon be available from markets for carbon sequestration and 'biodiversity offsets'. Assuming these markets require projects to demonstrate sequestration and biodiversity outcomes over many decades, in return for long-term funding, they could give practitioners a real opportunity and incentive to implement successful restoration projects.

\section{References}

Big Scrub Rainforest Landcare Group (2005) Subtropical Rainforest Restoration: Second Edition. Big Scrub Rainforest Landcare Group, Bangalow.

Catterall C. P., Kanowski J., Wardell-Johnson G. W., Proctor H., Reis T., Harrison D. and Tucker N. I. J. (2004) Quantifying the biodiversity values of reforestation: perspectives, design issues and outcomes in Australian rainforest landscapes. In: Conservation of Australia's Forest Fauna, Vol. 2 (ed. D. Lunney), pp. 359-393. Royal Zoological Society of NSW, Sydney.

Freebody K. (2007) Rainforest revegetation on the Atherton Tablelands, Wet Tropics, north Queensland: Planting models and monitoring requirements. Ecological Management \& Restoration 8, 140-43.

Goosem S. and Tucker N. I. J. (1995) Repairing the rainforest: Theory and practice of rainforest reestablishment in North Queensland's Wet Tropics. Wet Tropics Management Authority, Cairns.

Joseph R. (1999) An integrated, systematic approach to rainforest remnant restoration. In: Rainforest Remnants: a Decade of Growth (ed. S. Horton), pp. 168-180. NSW NPWS, Hurstville.

Kanowski J., Catterall C. P., McKenna S. and Jensen R. (2008a) Impacts of cyclone Larry on the vegetation structure of timber plantations, restoration plantings and rainforest on the Atherton Tableland, Australia. Austral Ecology 33, 485-494.

Kanowski J., Catterall C. P. and Neilan W. (2008b) The potential value of weedy regrowth for rainforest restoration. Ecological Management \& Restoration 9, 88-99.

Kanowski J., Kooyman R. M. and Catterall C. P. (2008c) Dynamics and restoration of Australian tropical and subtropical rainforests. In: New Models for Ecosystem Dynamics and Restoration (eds R. Hobbs and K. Suding), pp 206-220. Island Press, Washington D.C.

Kooyman R. (1996) Growing rainforest: Rainforest restoration and regeneration--Recommendations for the humid subtropical region of northern NSW and south-east Qld. Greening Australia, Brisbane.

Lymburner S., Handley C. and Handley J. (2006) Rainforest rehabilitation on a productive Macadamia property: The Brockley story. Ecological Management \& Restoration 7, 184-96.

Taylor R. (2009) Low success from rainforest revegetation investment. Ecos 33, 151. 
Tucker N. I. J. and Simmons T. (2009) Restoring a rainforest habitat linkage in north Queensland: Donaghy's Corridor. Ecological Management \& Restoration 10, 98-112.

Woodford R. (2000) Converting a dairy farm back to rainforest: the Rocky Creek Dam Story. Ecological Management \& Restoration 1, 83-92

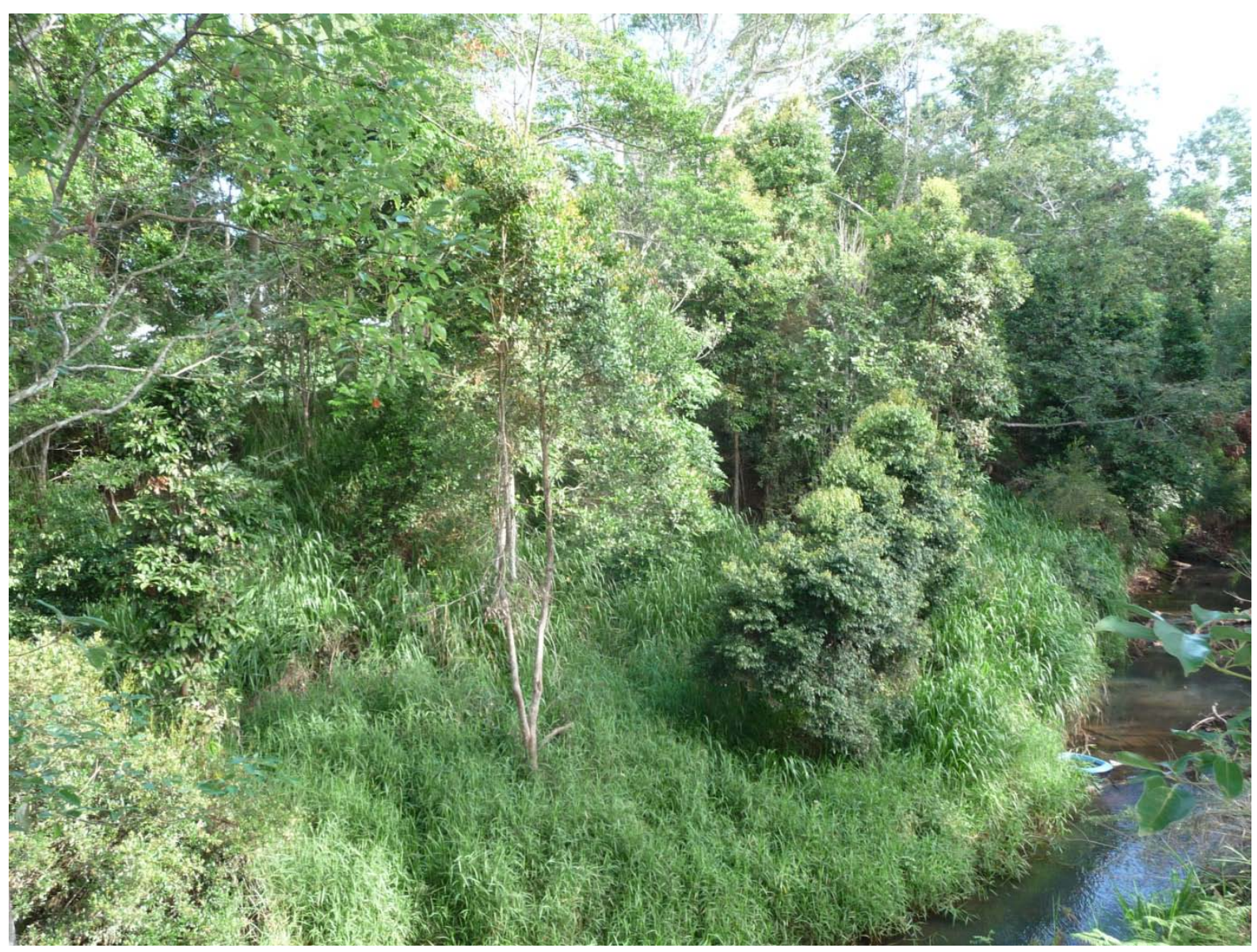

Figure 1. Dense grass under open canopy of 15 year old restoration planting along the Johnstone River, Malanda, north Queensland. 


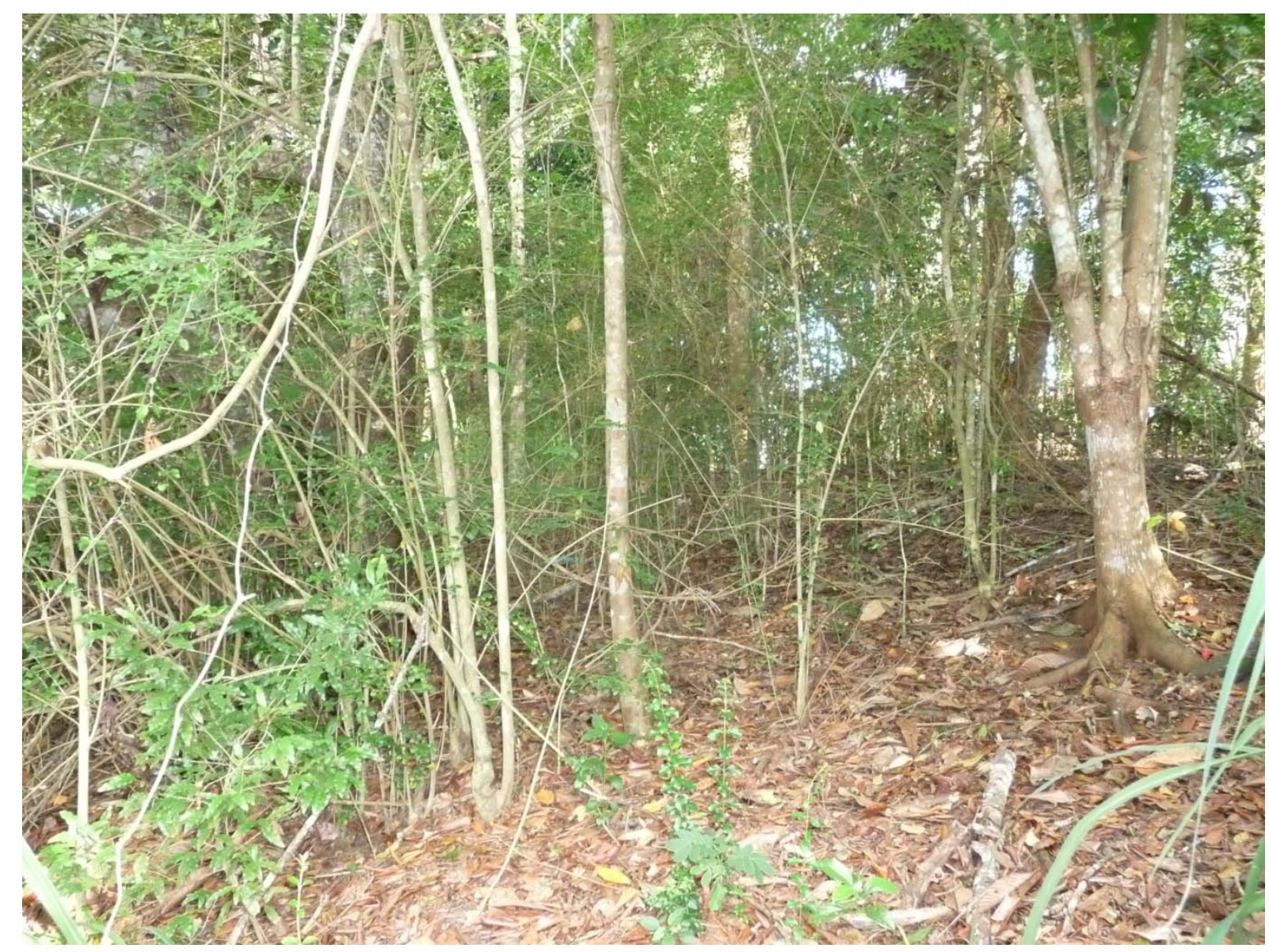

Figure 2. Dense recruitment of exotic shrubs under closed canopy of 15 year old restoration planting along the Johnstone River, Malanda, north Queensland. 


\section{[bionote:]}

Dr John Kanowski has worked for most of the last decade researching the biodiversity outcomes of rainforest restoration. In the last year he has been working as Regional Ecologist, north-east Australia, for the Australian Wildlife Conservancy" (E-mail: John.Kanowski@australianwildlife.org) 